\title{
Productive use of derivational morphology by deaf college students
}

\author{
VICKI L. HANSON \\ IBM Research Division, Thomas J. Watson Research Center, Yorktown Heights, New York
}

\begin{abstract}
The ability of deaf college students to take advantage of derivational morphology is examined in an experiment on vocabulary acquisition. Using a paired-associate task, the deaf subjects were found to learn pseudoword-word pairs faster when semantically related words (e.g., book and read) were paired with derivationally related pseudowords (e.g., RALP and RALPIFY) than when they were paired with unrelated pseudowords (e.g., NARK and STRITIFY). These results converge with evidence obtained in other studies in indicating that deaf students are able to take advantage of English morphology when reading.
\end{abstract}

Words that are derivationally related represent different syntactic categories but share a common lexical base. English derivations commonly occur by affixation, as in the pairs slow/slowly, fit/fitness, and help/helper. It is the common lexical base that leads to overlap, not just semantically but also orthographically and phonologically. For example, in English, the verb help and the noun helper are derivationally related and exhibit overlap at all three levels. In contrast, the verb read and noun book are semantically related but do not have the phonological and orthographic overlap required to be derivationally related.

If students have knowledge of morphological relationships among words, they may use it to their advantage in, for example, vocabulary acquisition (White, Power, $\&$ White, 1989). It has been estimated that normally hearing children learn approximately 3,000 new words per year between Grades 3 and 12 (Nagy \& Herman, 1987). Of these new words, only a few hundred are explicitly taught (Jenkins \& Dixon, 1983; Nagy \& Anderson, 1984; Nagy \& Herman, 1987). Approximately another one-third of their annual vocabulary growth is learned through context, during either reading or listening (Jenkins \& Dixon, 1983; Nagy, Anderson, \& Herman, 1987).

To account for the remaining vocabulary growth, researchers have begun to explore whether students can use morphology to infer word meanings from word parts. It has been found that by the fourth grade, students are able to use knowledge of derivational morphology to figure out the meanings of new words (Tyler \& Nagy, 1989). Since more than $60 \%$ of the new words that readers encounter are morphologically transparent (Nagy \& Anderson, 1984), potentially thousands of words per year could

This research was supported in part by Grant NS-18010 from the National Institute of Neurological and Communicative Disorders and Stroke to the author when she was at Haskins Laboratories. I thank Deborah Kuglitsch for her help with testing subjects and Carol Padden for her help with stimulus preparation. Correspondence should be addressed to V. L. Hanson, IBM Thomas J. Watson Research Center, P.O. Box 704, Yorktown Heights, NY 10598. be learned through application of morphological principles by the time children reach the seventh grade (White et al., 1989).

There is evidence that the ability to apply knowledge of morphological principles to vocabulary acquisition is one skill that distinguishes good from poor readers. Freyd and Baron (1982) asked whether superior students are better at taking advantage of morphological relatedness than are normally achieving students. In two tasks, differences between the superior and normally achieving students were obtained. The first task asked students to provide definitions of morphologically simple (e.g., equal, abrupt ) and complex (e.g., factual, limitless) words. Although the subjects in the two groups were equally capable of defining the morphologically simple words, the superior students (fifth graders) were more likely than were the normally achieving students (eighth graders) to be able to define the morphologically complex words. The second task was a paired-associate task in which the students were asked to learn the "meanings" of pseudowords. In this task, half of the pseudowords were related to another pseudoword in the list by a common base and derivational suffix. These morphologically related pseudowords were paired with semantically related real words. In this condition, the semantically related words book and read were paired, for example, with the morphologically related pseudowords RALP and RALPIFY to create the following two paired-associate items: RALP-book and RALPIFY-read. The other half of the pseudowords in the Freyd and Baron study were morphologically unrelated to any other pseudoword in the list. In this condition, unrelated pseudowords were paired with semantically related real words. For example, book and read were paired with the morphologically unrelated pseudowords, NARK-book and STRITIFY-read. By using this procedure, Freyd and Baron found that the superior students, but not the normally achieving students, learned the pairings for book and read more rapidly when they were paired with RALP and RALPIFY than when they were paired with NARK and STRITIFY. 
Vocabulary acquisition is an often cited problem area for deaf readers (Karchmer, Milone, \& Wolk, 1979; LaSasso \& Davey, 1987; Silverman-Dresner \& Guilfoyle, 1972). The present experiment investigated whether morphological relationships in English are exploited by deaf skilled readers. Focusing on derivational morphology, this experiment used the paired-associate task of Freyd and Baron (1982) to examine whether these students learn the "meanings" of morphologically related pseudoword pairs more readily than they learn the "meanings" of unrelated pseudoword pairs.

METHOD
Subjects
The subjects for the study were 16 undergraduates or recent gradu-
ates of Gallaudet University. All were prelingually, profoundly deaf with
hearing losses greater than $90 \mathrm{~dB}$, pure tone better ear average. Eleven
of these subjects had two deaf parents; another had a deaf sibling.
Reading achievement test results were available for 12 of the 16 sub-
jects. On the Gates-MacGinitie Reading Tests (1978) comprehension
subtest (Form E, Level 2), these subjects had a median reading grade
equivalent of 8.4 (range: grade 5.2-12.9+). Given that profoundly deaf
high school graduates only read, on average, at third-grade level (Con-
rad, 1979; Karchmer et al., 1979), the reading proficiency of the present
subject sample indicates considerably better reading ability than that of
the deaf population as a whole.

Stimuli

Twelve pairs of semantically related words were used. The word pairs were chosen so that the American Sign Language (ASL) signs corresponding to the two members of each pair were formationally distinct.

Pseudowords were generated so that there were six pairs that shared that same root and 6 pairs that did not. In each of the 12 pairs, however, one member of the pair was a root (or base) pseudoword and the other was a morphologically complex pseudoword. All pseudowords were pronounceable in English.

The words and pseudowords were taken, in part, from the study of Freyd and Baron (1982), although some words were changed to meet the requirement that the corresponding signs be formationally distinct. In addition, since the Freyd and Baron study was conducted with children, additional test items were added in the present study to make the task more challenging for college students. There were four noun-verb pairs, four verb-adjective pairs, and four noun-adjective pairs.

Two different test sets were constructed. In each set, half of the semantically related words were paired with morphologically related pseudowords. The two sets differed in that the words paired with the morphologically related pseudowords in one set were paired with the morphologically unrelated pseudowords in the other set. Thus, the two sets contained the same words and the same pseudowords; they differed only in the pairing of the words and pseudowords.

Each pseudoword was lettered in uppercase print on a $3 \times 5$-in. index card.

\section{Procedure}

The experimenter for the study was a deaf native signer of ASL who was a student at Gallaudet University. Communication between the experimenter and the subjects was signed.

The experimenter began the study by shuffling the deck of cards on which the pseudowords were printed. The subjects were informed that they would be seeing some nonsense words. Their task was to learn what each nonsense word "meant." The subjects were shown a card in the deck, with the experimenter signing, "Here is the word ," (pseudoword was fingerspelled). ${ }^{1}$ "It means " (the associated word was fingerspelled). The experimenter went through each card in the deck in this manner.

The testing then began. The experimenter would show the subject a card and then would sign, "What does this mean?" The subjects were encouraged to guess if they were not sure. Because individual signs may have more than one English word that corresponds in meaning, the subjects were instructed to always fingerspell their answer rather than signing it.

The experimenter went through the deck of cards either 12 times or until the subject had completed two trials with no errors. Half of the subjects were tested with each set.

\section{RESULTS}

All of the subjects reached criterion within the 12 trials allotted. The median number of trials per subject was 6.5 , ranging from 4 to 12 trials.

The data were scored relative to the number of errors made by the subjects. On the morphologically related items, the subjects made a mean of 15.8 errors, whereas on the morphologically unrelated items they made a mean of 24.6 errors. This difference in accuracy in the two conditions was highly significant $[t(15)=4.29, p<.001$, two-tailed].

However, as noted by Freyd and Baron (1982), scoring based solely on the number of errors in each condition is rather crude. In particular, if the subjects do indeed learn rules, then these rules should facilitate the learning of pairs of words. The rationale is that after one member of a pair is learned, the second member can be learned through application of the appropriate derivational principle. Bearing this in mind, the data were rescored to analyze the percentage of pairs in which each subject was correct on both members of a pair. Following Freyd and Baron, the final score was then the difference between these proportions for the morphologically related and unrelated pairs. A positive difference score indicates the application of morphological principles. The subjects were more accurate on the morphologically related pairs $(73.5 \%)$ than they were on the unrelated pairs $(57.8 \%)$. This difference, 15.7 , was significantly different from zero $[t(15)=6.27, p<.001$, two-tailed], indicating a clear ability to productively use derivational relationships. No subject was more accurate on the morphologically unrelated pairs than on the related pairs.

For the 12 subjects for whom reading scores were available, their reading proficiency was correlated with their difference score on learning pairs of words. This correlation was positive (.41), but not statistically significant with only 12 subjects. The positive score indicates, however, that the better readers tended to learn the morphologically related pairs faster than they did the unrelated pairs. This correlation for deaf students is consistent with Freyd and Baron's (1982) finding that in a hearing population, good readers were able to productively use derivational morphology to a greater degree than were poor readers.

\section{DISCUSSION}

A picture is now emerging in which it is clear that deaf college students are knowledgeable about English morphology and can use their knowledge of morphological relationships when dealing with printed English. Research has shown, for example, that deaf college students are more accurate at spelling words that can be derived through application of morphological principles than they are at spelling irregular words, such as sergeant and ache, that are not thus derivable (Hanson, 
Shankweiler, \& Fischer, 1983). In addition, other work has shown that deaf college students organize their lexicons along morphological principles of English (Hanson \& Feldman, 1989, 1991; Hanson \& Wilkenfeld, 1985). In these latter studies, subjects were facilitated in their responding to target words that were preceded by morphologically related words (e.g., sight preceded by see) but were not facilitated in their responding to target words that were preceded by words that shared only orthographic overlap (e.g., sight preceded by sigh). This pattern of results was interpreted, consistent with the pattern of results from repetition priming studies with hearing subjects, as indicating that morphologically related words are stored closely together in the internal lexicon.

The present study found further evidence that deaf college students take advantage of morphological principles. Like the group of academically advanced hearing fifth-grade students tested by Freyd and Baron (1982), the deaf college students in this study learned pseudoword-word pairs faster when semantically related words (e.g., book and read) were paired with derivationally related pseudowords (e.g., RALP and RALPIFY) than when they were paired with unrelated pseudowords (e.g., NARK and STRITIFY). These deaf subjects, therefore, appreciated that the orthographic and phonological overlap of the pseudoword root, combined with the derivational suffix, could be related to semantic overlap. They used this knowledge, this basis of morphological relatedness, when learning the "meanings" of pseudowords.

Deaf good readers' apparent ability to utilize morphological principles at the word level in this study and in earlier ones (e.g., Hanson \& Feldman, 1989; Hanson et al., 1983; Hanson \& Wilkenfeld, 1985) stands in marked contrast to research findings that deaf individuals exhibit difficulties in using grammatical morphology when writing (e.g., see Quigley \& King, 1980; Taeschner, Devescovi, \& Volterra, 1988). In particular, deaf writers make many errors in their use of free-standing functor words such as articles, prepositions, and pronouns. It has been suggested that the ability to use grammatical morphology may depend on phonological processes that may be difficult for congenitally deaf readers/writers to master (Hanson, 1991; Lichtenstein, 1985; Volterra \& Bates, 1989). In contrast, the ability to use morphological relationships related to internal word structure may be acquired through visual processes (Lichtenstein, 1985). In any event, it is clear that many morphological processes, such as those involved in lexical organization, spelling, and vocabulary acquisition, are used by deaf college students.

\section{REFERENCES}

Conrad, R. (1979). The deaf schoolchild. London: Harper \& Row. FREYD, P., \& BARON, J. (1982). Individual differences in acquisition of derivational morphology. Journal of Verbal Learning \& Verbal Behavior, 21, 282-295.

Gates-MacGinitie Reading Tests (2nd ed.) (1978). Boston: Houghton Mifflin.

Hanson, V. L. (1991). Phonological processing without sound. In S. Brady \& D. Shankweiler (Eds.), Phonological processes in literacy: A tribute to Isabelle Y. Liberman (pp. 153-161). Hillsdale, NJ: Erlbaum.

Hanson, V. L., \& FELdman, L. B. (1989). Language specificity in lexical organization: Evidence from deaf signers' lexical organization of American Sign Language and English. Memory \& Cognition, 17, 292-301.
Hanson, V. L., \& Feldman, L. B. (1991). What makes signs related? Sign Language Studies, 70, 35-46.

Hanson, V. L., Shankweiler, D., \& Fischer, F. W. (1983). Determinants of spelling ability in deaf and hearing adults: Access to linguistic structure. Cognition, 14, 323-344.

Hanson, V. L., \& Wilkenfeld, D. (1985). Morphophonology and lexical organization in deaf readers. Language \& Speech, 28, 269-280.

Jenkins, J. R., \& Dixon, R. (1983). Vocabulary learning. Contemporary Educational Psychology, 8, 237-260.

Karchmer, M. A., Milone, M. N., JR., \& Wolk, S. (1979). Educational significance of hearing loss at three levels of severity. American Annals of the Deaf, 124, 97-109.

LASASSO, C., \& DAVEy, B. (1987). The relationship between lexical knowledge and reading comprehension for prelingually, profoundly hearing-impaired students. Volta Review, 89, 211-220.

LiChTENSTEIN, E. H. (1985). Deaf working memory processes and English language skills. In D. S. Martin (Ed.), Cognition, education, and deafness: Directions for research and instruction (pp. 111-114). Washington, DC: Gallaudet College Press.

NAGY, W., \& ANDERSON, R. C. (1984). How many words are there in printed school English? Reading Research Quarterly, 19, 304-330.

Nagy, W., Anderson, R. C., \& Herman, P. A. (1987). Learning word meanings from context during normal reading. American Educational Research Journal, 24, 237-270.

NAGY, W. E., \& Herman, P. A. (1987). Breadth and depth of vocabulary knowledge: Implications for acquisition and instruction. In M. G. McKeown \& M. E. Curtis (Eds.), The nature of vocabulary acquisition (pp. 19-35). Hillsdale, NJ: Erlbaum.

Quigley, S., \& KING, C. (1980). Syntactic performance of hearing impaired and normal hearing individuals. Applied Psycholinguistics, 1, 329-356.

Silverman-Dresner, T., \& Guilfoyle, G. R. (1972). Vocabulary norms for deaf children. Washington, DC: Alexander Graham Bell Association for the Deaf.

Taeschner, T., Devescovi, A., \& Volterra, V. (1988). Affixes and function words in the written language of deaf children. Applied Psycholinguistics, 9, 385-401.

Tyler, A., \& NAGY, W. (1989). The acquisition of English derivational morphology. Journal of Memory \& Language, 28, 649-667.

Volterra, V., \&ATES, E. (1989). Selective impairment of Italian grammatical morphology in the congenitally deaf: A case study. Cognitive Neuropsychology, 6, 273-308.

White, T. G., PoWer, M. A., \& White, S. (1989). Morphological analysis: Implications for teaching and understanding vocabulary growth. Reading Research Quarterly, 24, 283-304.

\section{NOTE}

1. In fingerspelling, there is a handshape corresponding to each letter of the alphabet. Words are spelled out letter by letter with these handshapes.

(Manuscript received August 11, 1992.) 